\title{
Synthesis of 2-Amino-5-Substituted-1,3,4-Thiadiazoles (ATDA) and Their Derivatives Using Conventional and Microwave Techniques*
}

\author{
Moayed S. AL-Gwady \\ Department of Chemistry \\ College of Science \\ Mosul University
}

(Received 12/6/2008 ; Accepted 27/10/2008)

\begin{abstract}
A variety of 2-Amino-5-substituted -1,3,4-thiadiazoles (ATDA) were prepared by the reaction of thiosemicarbazide with different substituted carboxylic acids and phosphorous oxychloride as catalyst using conventional methods in comparison with the advantages of microwave techniques.

The 5-(substituted-1,3,4-thiadiazol-2-yl) carbamates derivatives were prepared by refluxing these (ATDA) with ethyl chloroformates using pyridine as a base to neutralize the acid produced which gave higher yield than sodium carbonate. The structures of the products were supported by IR spectroscopy.

Keywords: Thiadiazole, carbamates, microwave techniques.

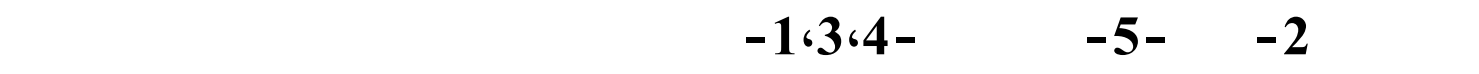 قليسة وميكروفف}

\section{الملغص}

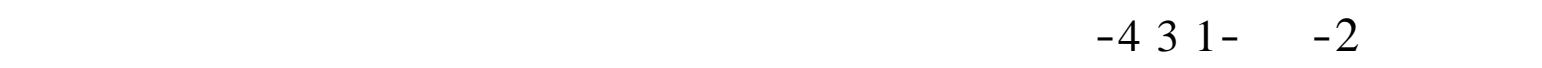
كاربوكسيلية مختلفة بوجود حلمض اوكس كلوريد الفوسفور كعلمل مساعد وبلستخدلم الط ـرق القليي ـة

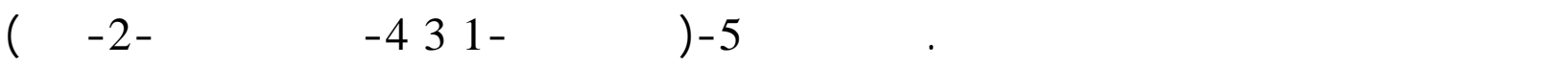
الكاربلملت من تصعيد هذه الأمينات مع كلوروفورمات الاثل بلستخدلم البريدين كفاعدة لمعادلة الحلمض الناتج والذي أعلى نسبة نانج أعلى من لستخدلم كربونات الصوديوم. مم دعم الترلكيب الكيميائية لذ ـواتج بلطيف الأشعة تهت الحمراء.
\end{abstract}

*م إلفاه بالمؤتمر العلهي الأول للكيمياء المنقد بتاريخ 22-23 نيسان 2008 فى قسم الكيمياء /كلية العلوم/ جلمعة الموصل 


\section{INTRODUCTION}

Several procedures were reported for the synthesis of 2-aminothiadiazoles, in many of these methods a thiosemicarbazide was the starting material. Among the most

important procedures described were the acylation of thiosemicarbazide to produce 1-acylthiosemicarbazide which then cyclized with a suitable dehydrating agent (Shmeiss et al., 2002).

Acylation was generally performed with an acid chloride and elimination of water from the intermediate was conveniently affected with cold concentrated sulfuric acid (Chubb, 1959; Ohta and Higashijimia, 2002; Solak and Rollas, 2006), 100\% phosphoric acid or phosphorous halides (Foxton et al., 1978 ; Saied, 1983).

The energy profile in a microwave-assisted this cyclization was directly absorbed by the reactant molecules (Ajay et al., 2001), and may be quite different from that in which the reaction mixture was heated conventionally by conduction/convection using concentrated sulfuric acid, phosphorous oxy chloride or phosphoric acid (Saied, 1983).

A number of methods for the synthesis of carbamates have been reported, the reactions of amines with alkyl chloroformates being the most common (Saied, 1983; Olofson, 1988).

As part of continuous program directed toward the studies with polyfunctionally substituted heterocycles (AL-Gwady et al., 2007), it was become of interest to investigate preparative routs to synthesize anticipated insecticidal active carbamate derivatives by the reactions of chloroformate with a variety of some 2-amino-5-substituted -1,3,4thiadiazoles (ATDA). These (ATDA) were synthesized by the reaction of thiosemicarbazide and substituted carboxylic acids using microwave irradiation with comparison with conventional method in which phosphorous oxychloride was used as catalyst.

\section{EXPERIMENTAL}

All melting points were determined on a Gallen Kamp and Electro thermal 1A9300 Digital-Series (1998) apparatus and were uncorrected. The IR-spectra were recorded on Perkin-Elmer 590B Spectrophotometer.

2-Amino-5-substituted-1,3,4 - thiadiazoles (ATDA) $(1$ a-g) and 2,6-bis (5-amino-1,3, 4-thiadiazol-2yl) pyridine 1(h):

Conventional method (a):(Saied, 1983 ; Kidwai et al., 1999)

Phosphorous oxychloride (4.6g,0.034mole) was added drop-wise to an ice cold mixture of $(0.9 \mathrm{~g}, 0.01 \mathrm{~mole})$ thiosemicarbazide powdered and $(0.01$ mole) of the proper carboxylic acid ( 0.005 mole for 2,6-pyridine dicarboxylic acid) with stirring, reflux was continued for one hour, cooled to room temperature, added to $250 \mathrm{ml}$ of stirred ice-cold water and neutralized with $10 \%$ sodium carbonate solution. The precipitated cyclized product was filtered, washed with water and crystallized from aqueous ethanol. Physical and spectral data were listed in Table (1).

Microwave irradiation method (b): (Kidwai, 2001; Aly et al., 2006; AL-Gwady et al., 2007)

The reaction mixture of ( $0.9 \mathrm{~g}, 0.01 \mathrm{~mole})$ thiosemicarbazide and ( $0.01 \mathrm{~mole})$ of the proper carboxylic acid ( 0.005 mole for 2,6-pyridine dicarboxylic acid) were mixed with a spatula for a few minute, placed in an opend conical flask in a domestic microwave oven 
(containing crucible of 2 gm magnesium sulfate) and irradiated for $5 \mathrm{~min}$. (the reaction was monitored by TLC to indicate the disappearance of the starting material). The resulting mixture was cooled, added to $250 \mathrm{ml}$ of stirred ice-cold water, neutralized with $10 \%$ sodium carbonate solution and worked up as in method (a).

Table 1: Phsical and spectral data of 2-Amino-5-substituted-1,3,4-thiadiazoles (ATDA) (1 a-g) and 2,6-bis (5-amino-1,3,4-thiadiazol-2yl) pyridine 1(h):

\begin{tabular}{|c|c|c|c|c|c|c|c|}
\hline \multirow{2}{*}{$\begin{array}{c}\text { Compd. } \\
\text { No.1 }\end{array}$} & \multicolumn{2}{|c|}{$\begin{array}{l}\text { Method/ } \\
\text { Yield \% }\end{array}$} & \multirow{2}{*}{$\mathbf{m p}{ }^{\circ} \mathrm{C}$} & \multirow{2}{*}{ Color } & \multicolumn{3}{|c|}{ IR, Nujol , $\mathrm{Cm}^{-1}$} \\
\hline & $\mathbf{A}$ & B & & & $\begin{array}{c}\mathrm{NH}_{2} \\
\text { (medium) }\end{array}$ & $\begin{array}{c}\mathrm{C}=\mathbf{N} \\
\text { (medium) }\end{array}$ & $\begin{array}{c}\mathrm{C}-\mathrm{S} \\
\text { (weak) }\end{array}$ \\
\hline $\mathrm{a}$ & 60 & 91 & $180-84$ & Brown & 3157 & 1623 & 625 \\
\hline $\mathrm{b}$ & 55 & 92 & 199-200 & Yellow & 3150 & 1623 & 625 \\
\hline C & 35 & 94 & $204-6$ & Gray & 3148 & 1628 & 620 \\
\hline d & 65 & 91 & $240-44$ & Pale yellow & 3148 & 1622 & 618 \\
\hline $\mathrm{e}$ & 60 & 88 & 167-69 & Brown & 3145 & 1624 & 618 \\
\hline $\mathrm{f}$ & 36 & 60 & $188-90$ & Yellow & 3144 & 1624 & 624 \\
\hline $\mathrm{g}$ & 30 & 80 & $210-12$ & Brown & 3149 & 1621 & 625 \\
\hline $\mathrm{h}$ & 70 & 91 & $\begin{array}{c}160 \\
\text { (decomposed) }\end{array}$ & Brown & 3155 & 1621 & 625 \\
\hline
\end{tabular}

Ethyl- N-(5-substituted-1,3,4-thiadiazol-2-yl) carbamates (2a - g) and Pyridine -2,6bis-ethyl-N-(1,3,4-thiadiazole) carbamate 1(h):

Method (a): (Morren, 1959)

(1.085 gm, 0.01 mole) of ethyl chloroformate was added drop-wise to a solution of 0.01 mole of proper amine in $15 \mathrm{ml}$ pyridine ( 0.005 mole for amine $1 \mathrm{~h}$ ). The reaction mixture was left at room temperature for one hour with occasional shaking. It was then poured onto $100 \mathrm{ml}$ ice water and the precipited carbamate was filtered, washed with water, dilute hydrochloric acid, then with water again and crystallized from aqueous ethanol. Physical data were listed in Table (2).

Method (b): (Petrow, 1959)

( $0.84 \mathrm{gm}, 0.01$ mole) of anhydrous sodium carbonate was added to a solution of 0.01 mole of the appropriate amine in $20 \mathrm{ml}$. absolute ethanol (0.005 mole for amine $1 \mathrm{~h})$., then (1.085 gm, 0.01 mole) of ethyl chloroformate was added drop wise.

The reaction mixture was refluxed for three hours, cooled to room temperature and poured onto $100 \mathrm{ml}$ ice water. The precipitated product was filtered, and worked up as in method(a).

Table 2:Yields, melting points and I.R. data of Ethyl- N-(5-substituted-1,3,4-thiadiazol-2yl) carbamates $(2 \mathrm{a}-\mathrm{g})$ and Pyridine -2,6-bis-ethyl-N-(1,3,4-thiadiazole) carbamate $1(\mathrm{~h})$ :

\begin{tabular}{|c|c|c|c|c|c|c|}
\hline \multirow{3}{*}{ Compound no.2 } & \multirow{2}{*}{\multicolumn{2}{|c|}{$\begin{array}{l}\text { Yield \% } \\
\text { Method }\end{array}$}} & \multirow{3}{*}{$\mathrm{mp}^{\circ} \mathrm{C}$} & \multicolumn{3}{|c|}{ IR, Nujol ,Cm ${ }^{-1}$} \\
\hline & & & & \multirow{2}{*}{$\begin{array}{c}\mathrm{N}-\mathrm{H} \\
\text { (medium) }\end{array}$} & \multirow{2}{*}{$\begin{array}{c}\mathrm{C}=\mathrm{O} \\
\text { (strong) }\end{array}$} & \multirow{2}{*}{$\begin{array}{c}\mathrm{C}=\mathrm{N} \\
\text { (medium) }\end{array}$} \\
\hline & $\mathrm{a}$ & $\mathrm{B}$ & & & & \\
\hline $\mathrm{a}$ & 85 & 80 & 108-09 & 3100 & 1720 & 1570 \\
\hline $\mathrm{b}$ & 85 & 80 & $170-72$ & 3150 & 1720 & 1595 \\
\hline $\mathrm{C}$ & 90 & 70 & $190-91$ & 3120 & 1728 & 1565 \\
\hline $\mathrm{d}$ & 90 & 73 & $137-39$ & 3300 & 1729 & 1565 \\
\hline $\mathrm{e}$ & 80 & 70 & $180-82$ & 3300 & 1730 & 1580 \\
\hline $\mathrm{f}$ & 62 & 30 & $210-12$ & 3200 & 1720 & 1585 \\
\hline g & 80 & 69 & $235-37$ & 3225 & 1730 & 1590 \\
\hline $\mathrm{h}$ & 93 & 73 & $155-56$ & 3280 & 1730 & 1575 \\
\hline
\end{tabular}




\section{RESULTS AND DISCUSSION}

Scheme (1) summarizes the synthetic route followed for the preparation of the title compounds.
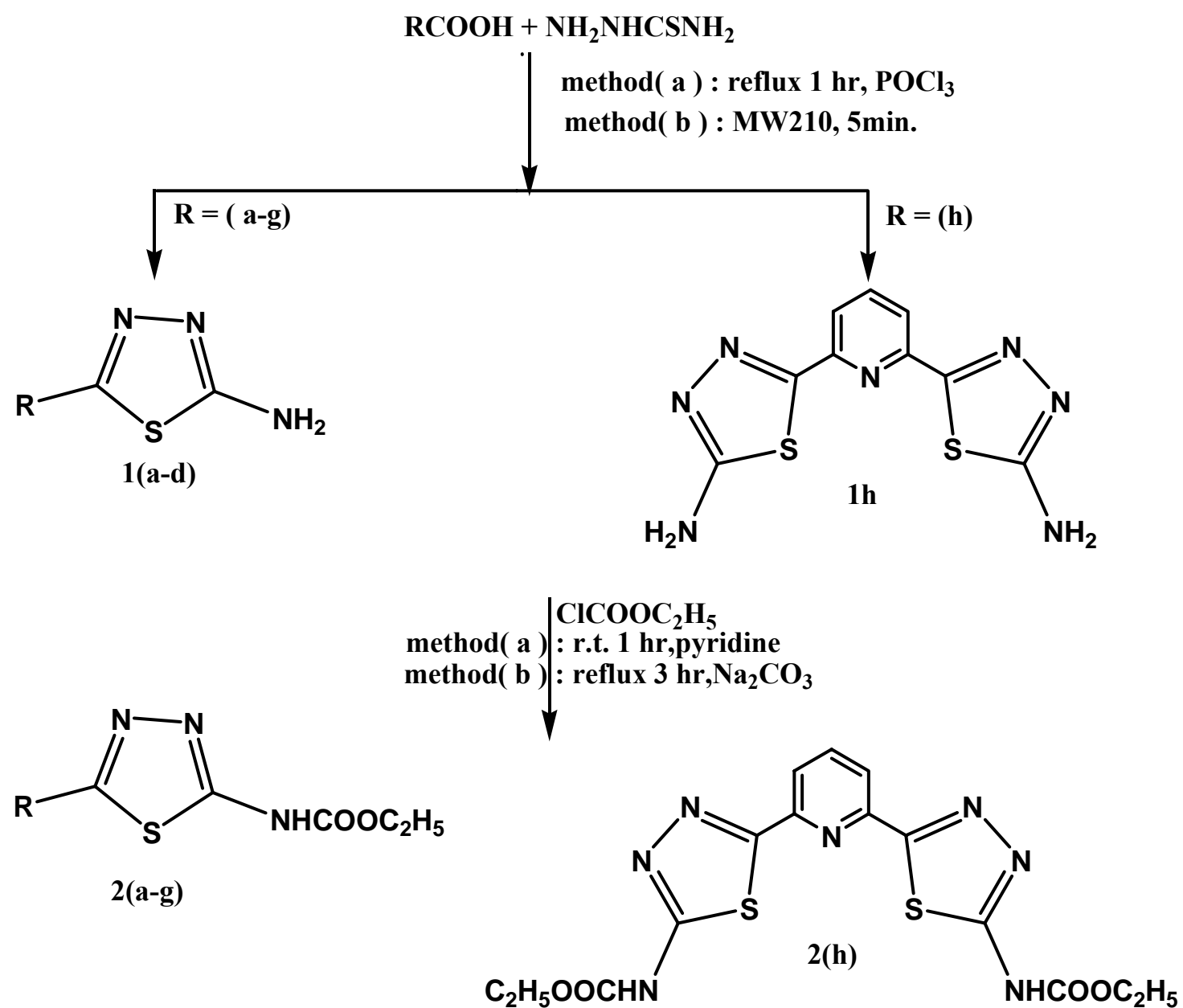<smiles>CCc1c[nH]c2ccccc12</smiles><smiles>CCc1cccnc1</smiles><smiles>Cc1cccnc1C(=O)O</smiles><smiles>CC1CCCC1</smiles>

$\mathbf{R}=$

(a)

(b)

(c)

(d)<smiles>Cc1ccc(-c2ccc([N+](=O)[O-])c([N+](=O)[O-])c2)cc1</smiles>

(e)

(f)

(g)

(h) 


\section{2-Amino-5-substituted-1,3,4-thiadiazoles (ATDA) (1 a-g) and 2,6-bis-(5-amino-} 1,3,4-thiadiazol-2yl) pyridine 1 (h):

Several procedures were reported for the synthesis of 2-amino-1,3,4-thiadiazoles, in many of these methods the thiosemicarbazide was the starting material. Among the most important procedures was the one step acylation and cyclization reaction which was achieved by heating the carboxylic acid with thiosemicarbazide in the presence of phosphorus halide (Foxton et al., 1978; Saied, 1983). In this work two methods were carried out, in method (a), the required 2-amino-5-substituted -1,3,4-thiadiazoles (1a-h) was synthesized by refluxing the proper carboxylic acids with a thiosemicarbazide in the presence of phosphorous oxychloride for one hour (Holan, 1960).

Scheme (2) summarizes the reaction mechanism probably proceeds in this method (Saied, 1983).

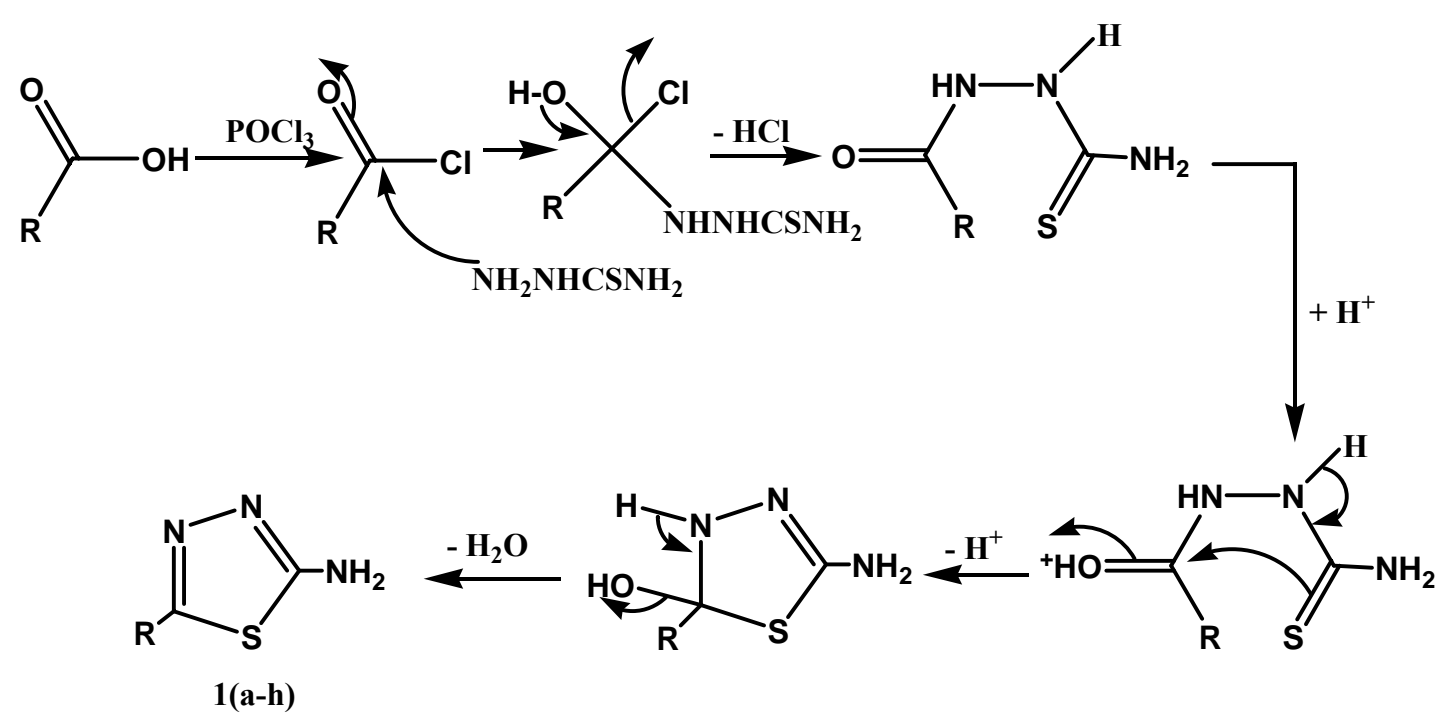

Scheme (2)

The disappearance of $\mathrm{C}=\mathrm{O}$ stretching in IR spectra was good indication of conversion of acid to heterocyclic ring, in addition to the following frequencies: 3144-3157 $\mathrm{Cm}^{-1}$ due to $\mathrm{NH}$ stretching, $1621-1628 \mathrm{Cm}^{-1}$ for $\mathrm{C}=\mathrm{N}$ stretching and this came in agreement to the published data (Hipler, 2002), and 618-625 $\mathrm{Cm}^{-1}$ for C-S ring stretching, Table (1).

In method (b) and to avoid the difficulty in processing (handling pollutant phosphorous oxychloride), to shorte the reaction time and to increase the yield (Kidwai, 2001; Aly et al., 2006), equimolar amounts of thiosemicarbazide and the appropriate acid were mixed together with $1 \%$ magnesium sulfate (as an additional microwave energy absorbant, the level of microwave energy required was reducedpresumably because of the attainment of higher efficiency of microwave energy absorption by the reaction mixture.), and the reaction mixture was irradiated in an open vessel in a domestic microwave oven for 5 minutes (Wilson,1971; Chaaban, 1984; Kidwai, 2001). The yield of these experiments ranged between $60 \%$ and $94 \%$, Table (1). 
It was worthy to mention that a double cyclization occurred in case of 2,6-pyridine dicarboxylic acid to give compound $1 \mathrm{~h}$,while steric effect prevent that to occurre in 2,3pyridine dicarboxylic acid.

\section{Ethyl- N-(5-substituted-1,3,4-thiadiazol-2-yl)carbamates (2a-g) and Pyridine -2,6- bis-ethyl-N-(1,3,4-thiadiazole) carbamate $1(\mathrm{~h})$ :}

Many routes in the literatures described the synthesis of carbamates (Metcalf et al., 1962; Armstrong et al., 1969), but the most suitable one which was adopted in this work is the reaction of amines with chloroformic ester (Iradj et al., 1971). The reactivity of chloroformic ester was comparable to that of acid chlorides and not ester due to the strong electron withdrawing inductive effect of adjacent chloride which increase the electrophilicity of carbonyl carbon (Izura et al., 1976; Tóth and Almásy, 2005).

Structures of these products were confirmed by their I.R. spectra which were identical to those published for similar compounds (Saied, 1983), and they were 3100-3300 Cm 1,medium for $\mathrm{NH}$ stretching, $1720-1730 \mathrm{Cm}-1$ strong for $\mathrm{C}=\mathrm{O}$ stretching and $1565-1595$, medium, for $\mathrm{C}=\mathrm{N}$ stretching, this decrease in the frequency (in comparison with that of compounds 1a-h) was due to the decrease of the force constant result from the resonance (produced by the conjugation effects

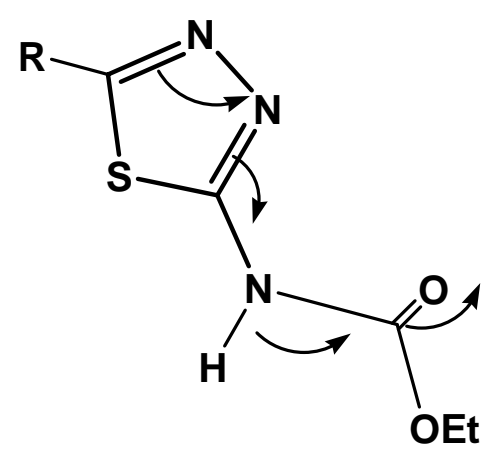
of carbamates groups) (Yukhnovskii, 1967) Scheme (3).

In method (a) Pyridine was used as a base to trap the acid produced at room temperature (Bender, 1960) which gave higher yields (62\%-93\%) while in method (b) in which the base was sodium carbonate with three-hour refluxed gave yields (30\%-80\%), Table(2).

\section{CONCLUSION}

Microwave irradiation in comparison with conventional methods resolved the important problems in cyclization of thiadiazoles 1(a-h) (the use of the pollutant dehydrating agent phosphorous oxychloride in addition to decrease the work time, increase the products yields, with simplicity in workup). The excellent crystal formation was due to magnesium sulfate. Finally, the new carbamates 2(a-h) were prepared with higher yields, short reaction time using pyridine as a base to trap the acid produced.

\section{REFERENCES}

Ajay, K.; Bose, Maghar, S.; Manhas, Subhendu, N.; Ganguly, Anju Sharma, Magaly Huarotte, Sochanchingwung Rumthao, Muthuswamy Jayaraman, and Bimal K., 2001, Fifth International Electronic Conference on Synthetic Organic Chemistry (ECSOC-5), Banik George Barasch Bioorganic Research Laboratory, Department of Chemistry and Chemical Biology, Stevens Institute of Technology, Hoboken, NJ 07030, USA.

AL Gwady, Moayed, S.; Saied, S.M., and Mohamad, S.J., 2007, A Comparative Studies Between Microwave And Conventional Techniques Using Different Catalysts To Synthesis of New Isobenzofurans, $10^{\text {th }}$ Scientific Conference for foundation of Technical Education Baghdad. 
Aly, A.A., and EL-Sayed, R., 2006. Synthesis and biological activity of new 1,3,4thiadiazole derivatives, Chem. Pap., 60(1), pp.56-60.

Armstrong, V.C., and Moodie, R.B., 1969. J.Chem.Soc., Sec.B., 934p.

Bender, M.I., 1960. Ghem. Rev.60, 53p.

Chaaban, I., and Oji., O.O., 1984. Synthesis and antibacterial activity of 3-(2-aryl amino1,3,4-thiadiazoles-5-yl) 4-hydroxy-4-substituted sulphamoyl benzene., J.Indian Chem. Soc., LXI, 523p.

Chubb, F.L., 1959. Synthesis of 2-Amino-1,3,4-thiadiazoles. Nissenbaum, J. Can. J. Chem. 1959, 37, 1121p.

Duta, M.M.; Goswami, B.N., and Kataky, J.C.S., 1987. Synthesis on biological active heterocyclics: Synthesis of some new 2-substituted-5-(2,4-dichlorophenyl)1,3,4-oxadiazoles and thiadiazoles, J.Indian. Chem. Soc., vol. LXIV, 195p.

Foxton, Michael, W.; Gregory, Gordon, I., and Rogers, D. M., (Ulverston, EN), 1978. 7,2-(Aminocarbonylalkoxyimino)acetamido! derivatives of cephalosporin; United States Patent 4074047

Hipler, F.; Fischer R.A., and Müller, J., 2002. Examining thermolysis reactions and tautomerism of 2-mercapto-5-methyl-1,3,4-thiadiazole and 2,5-dimercapto1,3,4-thiadiazole. J. Chem. Soc., Perkin Trans. 2, pp.1620-1622.

Iradj, L., and Vahdat, V, 1971. J. Med. Chem. 14(l), 59, C. A.; 74p.,87895.

Izura, Y.; Yohji, T., and K., Nobuo, 1976. Ger. Offen.,2,545,389, C. A. 85, 108434.

Kidwai, M.; Mishra, A.D., and Dave, B., 1999. Novel Synthesis Approach to New Thiadiazolo Aminotetrazoles, Synth Commun., 30p., 3031.

Kidwai, M., 2001. Dry media reactions, pure Appl.Chem,vol.73,No.1, pp.147-51.

Ohta, M., and Higashijimia, T., 1952. Preparation of 2-amino-5-alkyl-1,3,4-thiadiazoles, J. Pharm. Soc. Japan, 72, 376p.

Metcalf, R.L.; Fukuto, T.R., and Winton, M.Y. j., 1962. Econ. Entomol. 55, 889p.

Morren, H.G.; Belg., 1959. 562, 517, C.A., 85, 12305, 53.

Olofson, Roy A., 1988. New, useful reactions of novel haloformates and related reagents; fure and App/. Chern., Vol. 60, No. 11, pp.1715-1724.

Petrow, V.; Stephenson, O.A., and Tomas, A.j., 1959. Brit. 801. 349, C.A. 6255.

Saied, S.M., 1983. Synthesis of some heterocyclic derivatives Of anticipated insecticidal activity; MSC Thesis, College of pharmacy, Univ. of Baghdad, Iraq.

Shmeiss, N.A.M.M.; Ismail, I.M.M.; Soliman, A.M., and El-Diwani, H.I., 2002. Synthesis of Novel 1-Substituted and 1,9-Disubstituted-1,2,3,4-tetrahydro-9HCarbazole Derivatives as Potential AnticancerAgents. molecules; vol. 5; pp.1101-1112.

Solak, N., and Rollas, S., 2006. Synthesis and antituberculosis activity of 2(aryl/alkylamino)-5-(4-aminophenyl)-1,3,4-thiadiazoles and their Schiff bases. ARKIVOC (xii), pp.173-181.

Tóth, G., and Almásy, A., 2005. Isomerization and conjugation characteristics of the $\mathrm{C}=\mathrm{N}$ double bond. III $\dagger$ - 15N NMR studies of tautomerism in 2-phenylamino2-thiazoline and its thiazine analogue. Organic Magnetic Resonance; Volume 19 Issue 4, pp.219-221.

Wilson, W.E., and Clements, S.T., 1971. Science, 71p.

Yukhnovskii, N., 1967. Some effects of conjugation on the characteristic infrared, Theoretical and experimental chemistry, vol.3, No.1, pp.123-125. 